\title{
Makna aktivitas berorganisasi bagi mahasiswa aktivis jurusan ekonomi pembangunan UM angkatan 2018
}

\author{
Akbarti Na'ima, Sri Umi Mintarti Widjaja* \\ Universitas Negeri Malang, Jl. Semarang No. 5 Malang, Jawa Timur, Indonesia \\ *Penulis korespondensi, Surel: sri.umi.fe@um.ac.id
}

Paper received: 5-7-2021; revised: 23-7-2021; accepted: 30-7-2021

\begin{abstract}
In addition to studying at college, students choose to participate in organizing activities to fill their free time. However, joining students in the organization has a positive impact and a negative impact. Therefore, researchers conducted a study on the Meaning of Organized Activities for Activist Students of the Department of Economic Development um Class 2018. Researchers use qualitative methods with this type of case study approach in order to know and understand individuals more deeply about what is happening in the field according to the informant's personal experience. Determination of informants using purposive sampling with the criteria of students majoring in UM Development Economics class of 2018 who follow the organization. Data collection is done by means of in-depth interviews and documentation. Then, the data is reduced, presented, and drawn conclusions. Data validity checks are conducted through source triangulation and engineering inspection techniques. From the study found several findings that the Organization followed by 3 informants namely HMJ EKP while 2 others chose to follow BEM FEB UM. Students majoring in Development Economics class of 2018 have an achievement index in the neutral category above 3.50 and experienced an increase when following the organization, but some have experienced a decrease, but not significant. The advantages of interpreting organizing activities outside of academic achievement are gaining a lot of experience, gaining relationships, mastering public speaking, starting to understand various regional languages, understanding various backgrounds of people, knowing how to work teams, feeling the external experience of the campus, as well as better knowing how to communicate with many people.
\end{abstract}

Keywords: meaning of organized activities; student activists; department of development economics

\begin{abstract}
Abstrak
Selain belajar di perguruan tinggi, mahasiswa memilih mengikuti kegiatan berorganisasi untuk mengisi waktu luangnya. Namun, bergabungnya mahasiswa dalam organisasi memberikan dampak positif dan dampak negatif. Oleh karena itu peneliti melakukan penelitian tentang Makna Aktivitas Berorganisasi Bagi Mahasiswa Aktivis Jurusan Ekonomi Pembangunan UM Angkatan 2018. Peneliti menggunakan metode kualitatif dengan jenis pendekatan studi kasus agar dapat mengetahui dan memahami individu lebih mendalam tentang apa yang terjadi di lapangan sesuai dengan pengalaman pribadi informan. Penentuan informan menggunakan purposive sampling dengan kriteria mahasiswa jurusan Ekonomi Pembangunan UM angkatan 2018 yang mengikuti organisasi. Pengumpulan data dilakukan dengan cara wawancara mendalam dan dokumentasi. Kemudian, data direduksi, disajikan, dan ditarik kesimpulan. Pemeriksaan keabsahan data dilakukan melalui teknik pemeriksaan triangulasi sumber dan teknik. Dari penelitian ditemukan beberapa temuan yaitu Organisasi yang di ikuti oleh 3 informan yaitu HMJ EKP sementara 2 lainnya memilih mengikuti BEM FEB UM. Mahasiswa jurusan Ekonomi Pembangunan angkatan 2018 memiliki indeks prestasi dalam kategori netral di atas 3,50 dan mengalami kenaikan ketika mengikuti organisasi, namun diantaranya pernah mengalami penurunan, tetapi tidak signifikan. Keuntungan dari memaknai kegiatan berorganisasi di luar prestasi akademik yaitu mendapatkan banyak pengalaman, mendapatkan relasi, menguasai public speaking, mulai memahami berbagai macam bahasa daerah, mengerti berbagai macam latar belakang orang, mengetahui caranya kerja tim, merasakan pengalaman eksternal kampus, serta lebih mengetahui cara berkomunikasi dengan banyak orang.
\end{abstract}

Kata kunci: makna aktivitas berorganisasi; mahasiswa aktivis; jurusan ekonomi pembangunan

This work is licensed under a Creative Commons Attribution-ShareAlike 4.0 International License. 


\section{Pendahuluan}

Mahasiswa adalah peserta didik yang sudah melewati berbagai macam jenjang pendidikan, sehingga nantinya seorang mahasiswa mampu menjadi anggota masyarakat yang berguna dan memiliki kemampuan khusus baik dalam hal akademik maupun profesionalitasnya. Mahasiswa menyandang tiga fungsi strategis, yaitu sebagai penyampai kebenaran, agen perubahan, generasi penerus masa depan (Febriana, dkk 2013). Selain sebagai mahasiswa yang tugasnya belajar, sebagian dari mereka memilih kuliah sambil mengikuti kegiatan berorganisasi untuk mengisi waktu luang nya. Organisasi kemahasiswaan merupakan suatu wadah pengembangan diri mahasiswa yang dapat memainkan tiga fungsi strategisnya (Febriana, dkk 2013).

Keputusan Menteri Pendidikan dan Kebudayaan Nomor 155/U/1998 tentang Pedoman Umum Organisasi Kemahasiswaan dijelaskan bahwa organisasi kemahasiswaan adalah wahana dan sarana pengembangan diri mahasiswa ke arah perluasan wawasan dan peningkatan kecendekiawanan serta integritas kepribadian untuk mencapai tujuan pendidikan tinggi (Caesari dkk, 2016). Dengan mengikuti organisasi mahasiswa dapat memperluas wawasan, menyalurkan bakat, minat serta membentuk suatu pribadi yang kritis dimana hal ini tidak diperoleh di dalam kelas yang formal. Pilihan kegiatan kemahasiswaan harus sesuai dengan minat dan bakat mahasiswa karena kegiatan tersebut merupakan sarana pelengkap pembinaan kemampuan pribadi sebagai calon intelektual di masyarakat nantinya (Astuti, dkk 2017).

Organisasi mahasiswa yang ada di Fakultas Ekonomi dan Bisnis Universitas Negeri Malang adalah Badan Eksekutif Mahasiswa Fakultas Ekonomi \& Bisnis (BEM FEB), Himpunan Mahasiswa Jurusan (HMJ), dan beberapa Organisasi Sub Bidang atau yang dikenal sebagai Lembaga Semi Otonom (LSO).

Menurut Nursyamsi, dkk 2019 memberikan pendapatnya mengenai dampak pengalaman berorganisasi yaitu memberikan bekal kepada lulusan perguruan tinggi dalam berbagai hal, antara lain kemampuan berinteraksi, kemampuan berkomunikasi, kemampuan berpikir logis-sistematis, kemampuan menyampaikan gagasan di muka umum.

Masalah yang sering dijumpai di jurusan Ekonomi Pembangunan Universitas Negeri Malang (EKP UM) dimana beberapa mahasiswa jurusan EKP UM yang terlibat aktif di organisasi cenderung memiliki sikap menunda pekerjaan, misalnya dalam hal mengerjakan tugas-tugas kuliah maupun penundaan untuk hadir di perkuliahan. Jika hal tersebut berlangsung secara terus menerus maka dikhawatirkan indeks prestasi nya tidak stabil dan dapat mengalami penurunan.

Mahasiswa yang aktif berorganisasi harus pandai mengatur waktu belajarnya. Keaktifan berorganisasi memberikan berbagai ilmu dan pengalaman yang baru di luar kegiatan perkuliahan. Mahasiswa yang aktif berorganisasi diharapkan mampu memperoleh hasil belajar yang lebih baik dan bisa berprestasi. Salah satu prestasinya yang diharapkan adalah memperoleh indeks prestasi (IP) yang optimal.

\section{Metode}


Peneliti menggunakan metode kualitatif, dengan menggunakan metode kualitatif data yang ditemukan berupa uraian kata-kata tertulis dari temuan yang diamati. Peneliti memilih metode kualitatif dengan pertimbangan bahwa masalah dalam penelitian ini membutuhkan pengamatan secara mendalam untuk mengungkapkan fakta-fakta yang ditemui di lapangan.

Dalam pelaksanaan penelitian, penulis menggunakan jenis pendekatan studi kasus. Tujuan dari penggunaan pendekatan studi kasus adalah untuk mengetahui dan memahami individu lebih mendalam tentang apa yang terjadi di lapangan sesuai dengan pengalaman pribadi informan. Pada awal penelitian, penulis akan mencari mahasiswa jurusan Ekonomi Pembangunan angkatan 2018 yang mengikuti organisasi. Setelah memperoleh informan yang tepat maka peneliti akan mulai menggali informasi dengan mewawancarai informan yang bersangkutan untuk mendapatkan informasi yang lebih mendalam mengenai Makna Aktivitas Berorganisasi Bagi Mahasiswa Aktivis Jurusan Ekonomi Pembangunan Angkatan 2018 berdasarkan temuan yang terjadi di lapangan.

Kehadiran peneliti pada penelitian ini adalah sebagai pengumpul data, penganalisis data, dan pelapor hasil penelitian. Dalam pengumpulan data, peneliti turun langsung ke lapangan karena peneliti bertindak sebagai pengumpul data utama. Peneliti melakukan wawancara dan dokumentasi kepada para informan sebagai langkah untuk memperoleh data yang akurat. Setelah memperoleh data hasil penelitian, peneliti melakukan penganalisisan data yang selanjutnya dilakukan proses pelaporan hasil penelitian.

Sumber data penelitian yang digunakan dalam penelitian ini merupakan sumber data primer. Dimana untuk mendapatkan data-data penelitian, peneliti mendapatkan langsung dari informan. Penentuan informan dalam penelitian ini adalah dengan menggunakan purposive sampling yaitu peneliti memilih orang-orang tertentu sesuai kriteria yang dapat memberikan informasi yang diperlukan.

\section{Hasil dan Pembahasan}

Dari hasil penelitian Makna Aktivitas Berorganisasi Bagi Mahasiswa Aktivis Jurusan Ekonomi Pembangunan Angkatan 2018 yaitu mereka memiliki keuntungan yang berbedabeda, diantaranya menambah wawasan/pengetahuan, memiliki pergaulan yang luas, belajar mengatur waktu, membentuk pola pikir yang lebih baik, menjadi kuat dalam menghadapi tekanan, meningkatkan kemampuan berkomunikasi, dan melatih kepemimpinan. Hal ini sejalan dengan yang dikemukakan oleh Kurniawati, dkk (2013) bahwa kegiatan organisasi memiliki keuntungan yaitu melatih mahasiswa untuk belajar hidup bermasyarakat, belajar untuk memecahkan berbagai permasalahan, dan mendapat ilmu yang tidak didapat dalam perkuliahan.

Selain itu mahasiswa jurusan EKP UM 2018 memiliki potensi yaitu sikap mudah tanggap dalam materi perkuliahan. Mahasiswa yang mengikuti kegiatan di organisasi dapat membagi waktunya, dan mampu memprioritaskan perkuliahan nya terlebih dahulu seperti menyelesaikan tugas yang diberikan dosen sehingga dapat melakukan manajemen waktu dengan baik dan sudah selesai mengerjakan tugas ketika pengumpulan deadline. Hal ini sejalan dengan yang dikemukakan oleh Setyaningrum dkk, (2018) bahwa mahasiswa yang berorganisasi mampu memiliki sikap untuk menyusun agenda dan prioritas kegiatan yang dilakukan dan dikuatkan oleh penelitian yang dilakukan Rahmaningsih, A. A. (2017) yang menyatakan bahwa dengan mengikuti organisasi atau kegiatan kampus mahasiswa dapat lebih aktif dalam kelas, dan mampu mengikuti pelajaran yang disampaikan di kelas. Mahasiswa yang 
aktif berorganisasi juga mendapatkan pengetahuan baru dari organisasi yang dapat menunjang perkuliahan nya.

Namun, kenyataan nya terdapat beberapa fakta bahwa informan yang mengikuti organisasi indeks prestasinya menurun. Hal ini dikarenakan informan masih mengerjakan tugas dengan sistem kebut semalam atau mengerjakan mendekati deadline tugas dikumpulkan, yang menyebabkan informan tidak optimal dalam mengerjakan tugasnya yang berakibat pada menurunnya indeks prestasi. Hal ini sejalan dengan penelitian yang dilakukan Nurgianto dalam Atamimi 2014 yang menyatakan bahwa peran aktif berorganisasi merupakan faktor sosial yang turut berpengaruh terhadap prestasi akademik mahasiswa.

Keuntungan dari kegiatan berorganisasi mahasiswa jurusan Ekonomi Pembangunan angkatan 2018 diluar prestasi akademik nya yaitu sebagian besar menjelaskan bahwa mereka mendapatkan banyak pengalaman, mendapatkan relasi, menguasai public speaking, mulai memahami berbagai macam bahasa daerah, mengerti berbagai macam latar belakang orang, mengetahui caranya kerja tim, merasakan pengalaman eksternal kampus, serta lebih mengetahui cara berkomunikasi dengan banyak orang. Hal ini sejalan dengan penelitian yang dilakukan Dina Fitriani, (2020) yang menyebutkan bahwa mahasiswa yang aktif berorganisasi mampu berkomunikasi, bersosialisasi, berinteraksi dengan baik, dapat bertukar pemikiran dengan anggota yang lain, mencari pengalaman, serta menambah wawasan.

Dengan mengikuti organisasi mahasiswa memiliki wawasan yang luas sehingga mempengaruhi cara berpikir yang pada dasarnya tidak diajarkan dalam perkuliahan di perguruan tinggi. Hal ini sejalan dengan penelitian yang dilakukan oleh Nurfadila, N. (2018) yang menyebutkan bahwa aktif dalam mengikuti organisasi kemahasiswaan akan berefek pada perubahan yang signifikan terhadap wawasan, cara berpikir, pengetahuan mengenai sosialisasi, dan manajemen kepemimpinan yang pada dasarnya tidak diajarkan dalam kurikulum normatif perguruan tinggi. Hal ini juga dikemukakan oleh penelitian yang dilakukan Prastiawan, (2009:15) dalam Kurnia, H. (2014) yang menyatakan bahwa kegiatan organisasi merupakan aspek eksternal yang dapat menunjang prestasi akademik mahasiswa, karena pengalaman dan pelajaran tersebut tidak didapatkan dalam bangku perkuliahan.

\section{Simpulan}

Berdasarkan hasil penelitian Makna Aktivitas Berorganisasi Bagi Mahasiswa Aktivis Jurusan Ekonomi Pembangunan Angkatan 2018 ada pada kategori netral, dimana mereka mengalami kenaikan indeks prestasi ketika mengikuti organisasi, namun diantaranya pernah mengalami penurunan, tetapi tidak signifikan. Mahasiswa yang indeks prestasi nya naik dikarenakan dapat membagi waktu antara kuliah, tugas kuliah dan organisasi. Mahasiswa tersebut menyatakan bahwa pembagian waktu antara kuliah dan organisasi dapat dilakukan jika memiliki rasa tanggung jawab terhadap kuliah.

Penurunan indeks prestasi dikarenakan mahasiswa belum mampu membagi waktu antara kuliah dan berorganisasi. Meskipun indeks prestasi nya menurun, sebenarnya mahasiswa yang berorganisasi tetap mengusahakan agar mendapatkan prestasi akademik yang baik.

Selain dari sisi akademik, dari kegiatan berorganisasi Mahasiswa Jurusan Ekonomi Pembangunan Angkatan 2018 mengaku bahwa mereka mendapatkan banyak pengalaman, mendapatkan relasi, menguasai public speaking, mulai memahami berbagai macam bahasa 
daerah, mengerti berbagai macam latar belakang orang, mengetahui caranya kerja tim, merasakan pengalaman eksternal kampus, serta lebih mengetahui cara berkomunikasi dengan banyak orang.

Untuk mahasiswa yang mengikuti organisasi indeks prestasi nya mengalami kenaikan diharapkan tetap mempertahankan konsistensi nya. Sebaliknya mahasiswa yang mengikuti organisasi tetapi indeks prestasi nya menurun diharapkan dapat mengatur waktunya antara kuliah dan berorganisasi agar prestasi akademiknya bisa lebih baik, mengingat tujuan utama seorang mahasiswa adalah untuk belajar dan berprestasi.

\section{Daftar Rujukan}

Ade, M. (2014). Dampak Organisasi pada Aktivitas Belajar Mahasiswa (Studi Kasus pada Organisasi IPPM Pangkep Koordinator Unm di Makassar). Skripsi, Fakultas Ilmu Sosial, Universitas Negeri Makassar. Dibimbing oleh Mustakim Nur Johar dan M. Ridwan Said Ahmad (Doctoral Dissertation, Universitas Negeri Makassar). (Online), (http://eprints.unm.ac.id/411/).

Aditama, R. (2018). Implementasi Metode K-Nearest Neighbor untuk Prediksi Indeks Prestasi Mahasiswa di STMIK Akakom (Doctoral Dissertation, Stmik Akakom Yogyakarta). (Online), (https://eprints.akakom.ac.id/8195/).

Afifah, A. A. N., \& Syah, M. F. J. (2019). Dampak Volunteering untuk Meningkatkan Interpersonal Skill Mahasiswa Pendidikan Akuntansi Universitas Muhammadiyah Surakarta (Doctoral Dissertation, Universitas Muhammadiyah Surakarta). (Online), (http://eprints.ums.ac.id/74565/).

Apiwie, P. W. (2013). Perbedaan Prestasi Belajar antara Mahasiswa Jurusan Sejarah Fakultas Ilmu Sosial Universitas Negeri Semarang Angkatan 2008 yang Aktif dan tidak Aktif dalam Organisasi Kemahasiswaan (Doctoral dissertation, Universitas Negeri Semarang). (Online), (https://lib.unnes.ac.id/18081/).

Biro Akademik, Kemahasiswaan, Perencanaan, Informasi, dan Kerjasama BAKPIK. (2020). Organisasi Kemahasiswaan. (Online). (http://bakpik.um.ac.id/kemahasiswaan2/kemahasiswaan/organisaskemahasiswaan).

Caesari, Y. K., \& Listiara, A. (2013). "Kuliah versus Organisasi” Studi Kasus Mengenai Strategi Belajar pada Mahasiswa yang Aktif dalam Organisasi Mahasiswa Pecinta Alam Universitas Diponegoro. Jurnal $\begin{array}{lll}\text { Psikologi, 12(2), 164-175. } & \text { (Online), }\end{array}$ (https://ejournal.undip.ac.id/index.php/psikologi/article/view/8835).

Creswell, J. W., \& Poth, C. N. (2016). Qualitative Inquiry and Research Design: Choosing Among Five Approaches. Sage Publications.

Deagustami, R., Pargito, P., \& Widodo, S. (2013). Hubungan antara Keikutsertaan Mahasiswa dalam Kegiatan Organisasi Kemahasiswaan. Jurnal Penelitian Geografi, 1(8). (Online), (http://jurnal.fkip.unila.ac.id/index.php/JPG/article/view/2447).

Dina Fitriani, U., Zulqarnain, Z., \& Nurbaiti, N. (2020). Dampak Berorganisasi terhadap Self Esteem (Harga Diri) Mahasiswa Fakultas Dakwah UIN Sulthan Thaha Saifuddin Jambi (Doctoral Dissertation, Uin Sulthan Thaha Saifuddin Jambi). (Online), (http://repository.uinjambi.ac.id/3089/).

Dwi Astuti, R. (2018). Kesiapan Kerja Mahasiswa Ditinjau dari Perilaku Entrepreneur dan Keaktifan Berorganisasi pada Mahasiswa Pendidikan Akuntansi FKIP-UMS Angkatan Tahun 2014 (Doctoral dissertation, Universitas Muhammadiyah Surakarta). (Online), (http://eprints.ums.ac.id/61688/).

Dwikornida, D., \& Boiziardi, A. S. (2017). Dampak Bekerja terhadap Prestasi Belajar Mahasiswa Universitas Tamansiswa Padang. Unes Journal of Swara Justisia, 1(3), 364-383. (Online), (http://swarajustisia.unespadang.ac.id/index.php/UJSJ/article/view/43).

Efendi, H. (2017). Hubungan Keaktifan Berorganisasi dengan Tingkat Manajemen Waktu dan Indeks Prestasi Kumulatif pada Mahasiswa Angkatan Tahun 2013 di Fakultas Kedokteran Universitas Lampung. (Online), (http://digilib.unila.ac.id/id/eprint/29994).

Febriana, B., Winanti, L., \& Amelia, S. (2017, February). Hubungan Antara Keaktifan Organisasi dengan Prestasi Belajar (Indeks Prestasi) Mahasiswa Fakultas Ilmu Keperawatan Universitas Indonesia. In PROSIDING $\begin{array}{llll}\text { SEMINAR NASIONAL \& INTERNASIONAL. } & \text { (Online), }\end{array}$ (http://103.97.100.145/index.php/psn12012010/article/view/868). 
Guetterman, T. C., Sakakibara, R. V., Clark, V. L. P., Luborsky, M., Murray, S. M., Castro, F. G., ... \& Gallo, J. J. (2019). Mixed Methods Grant Applications in the Health Sciences: An Analysis of Reviewer Comments. PloS One, 14(11).

(Online), (https://journals.plos.org/plosone/article/file?type=printable\&id=10.1371/journal.pone.0225308).

Halimah, F. (2013). Studi Korelasi Rata-Rata Nilai Ujian Akhir Madrasah (Uam) Mahasiswa Pai Iain Walisongo Semarang Dengan Indeks Prestasi Semester 1 Angkatan 2012 (Doctoral Dissertation, Iain Walisongo). (Online), (http://eprints.walisongo.ac.id/1592/).

Hipjillah, A., \& Badriyah, N. (2016). Mahasiswa Bekerja Paruh Waktu; antara Konsumsi dan Prestasi Akademik (Studi pada Mahasiswa Bekerja Paruh Waktu di Uno Board Game Cafe). Jurnal Ilmiah Mahasiswa Feb, 3(2). (Online), (https://jimfeb.ub.ac.id/index.php/jimfeb/article/view/1764).

Imron, I. (2019). Pengaruh Gaya Kepemimpinan, Kerjasama Tim, dan Budaya Organisasi terhadap Prestasi Kerja dan Dampaknya kepada Kinerja Pegawai. JEM Jurnal Ekonomi dan Manajemen, 5(1), 64-83. (Online), (http://www.stiepertiba.ac.id/ojs/index.php/jem/article/view/66).

Indonesia, P. (1998). Keputusan Menteri Pendidikan dan Kebudayaan Republik Indonesia Nomor 155/U/1998 Tentang Pedoman Umum Organisasi Kemahasiswaan di Perguruan Tinggi Menteri Pendidikan dan Kebudayaan. Jakarta: Sekretariat Negara.

Jurusan Ekonomi Pembangunan, Fakultas Ekonomi Univesitas Negeri Malang. (2020). Kegiatan Kemahasiswaan. (Online). (http://ekp.fe.um.ac.id/?page_id=2523).

Kurniawati, R., \& Leonardi, T. (2013). Hubungan antara metakognisi dengan prestasi akademik pada mahasiswa fakultas psikologi universitas airlangga yang aktif berorganisasi di organisasi mahasiswa tingkat fakultas. Jurnal Psikologi Pendidikan dan Perkembangan, 2(01), 1-6. (Online) (http://www.journal.unair.ac.id/filerPDF/jppp8592e834fc2full.pdf).

Lidinillah, D. A. M., \& Abdul, D. (2013). Perencanaan Strategis Untuk Organisasi Kemahasiswaan. (Online), (Http://File.Upi.Edu/Direktori/Kd-Tasikmalaya/Dindin_Abdul_Muiz_Lidinillah_(Kd-Tasikmalaya) $197901132005011003 / 132313548 \% 20$ \%20dindin\%20abdul\%20muiz\%20lidinillah/Strategic\%20planning.Pdf).

Muis, A. (2014). Konflik Interpersonal dan Pengelolaan Konflik Antarkelompok dalam Organisasi Kemahasiswaan (Studi Kasus Pada Organisasi X) (Doctoral Dissertation, Universitas Brawijaya). (Online), (http://repository.ub.ac.id/107266/).

Munahar, S. (2019). Analisis Dampak Pemanfaatan Waktu Luang di Kampus terhadap Prestasi Belajar $\begin{array}{llll}\text { Mahasiswa. } & \text { Islamika, 22-31. } & \text { (Online) }\end{array}$ (https://ejournal.stitpn.ac.id/index.php/islamika/article/view/151).

Mustofa, I. (2019). Pengaruh Keaktifan Mahasiswa dalam Organisasi Intra Kampus terhadap Proses Perkuliahan Mahasiswa Fakultas Pendidikan Teknologi dan Kejuruan Universitas Pendidikan Indonesia (Doctoral Dissertation, Universitas Pendidikan Indonesia). (Online), (http://repository.upi.edu/48251/).

Nur, T. (2016). Dampak Kuliah Sambil Bekerja terhadap Indeks Prestasi Komulatif(IPK) Mahasiswa (Studi Kasus Pada Jurusan Pengembangan Masyarakat Islam Pmi-Kesos Ar-Raniry Banda Aceh) (Doctoral Dissertation, Uin Ar-Raniry Banda Aceh). (Online), (https://repository.arraniry.ac.id/id/eprint/3798/).

Nurfadila, N., Munir, M. A., \& Rasyid, M. (2018). Pengaruh Keaktifan Berorganisasi Terhadap Indeks Prestasi Mahasiswa Di Fakultas Kedokteran Universitas Tadulako Tahun 2018. Medika Tadulako: Jurnal Ilmiah Kedokteran Fakultas Kedokteran Dan Ilmu Kesehatan, 6(2), 20-29. (Online), (http://jurnal.untad.ac.id/jurnal/index.php/MedikaTadulako/article/view/13254).

Nursyamsi, N. (2020). Flow Pada Mahasiswa Aktif Berorganisasi Di Universitas Andalas (Doctoral Dissertation, Universitas Andalas). (Online), (http://scholar.unand.ac.id/50038/).

Qayyum, Q., Akib, H., \& Darwis, M. (2019). Pengaruh Partisipasi dalam Organisasi terhadap Prestasi Belajar Mahasiswa Fakultas Ilmu Sosial Universitas Negeri Makassar. Universitas Negeri Makassar. (Online), (http://eprints.unm.ac.id/11778/1/JURNAL\%20QAYYUM\%201466040013.pdf).

Rachmah, D. N., Mayangsari, M. D., \& Akbar, S. N. (2015). Motivasi belajar sebagai mediator hubungan kecerdasan adversitas dan prokrastinasi akademik pada mahasiswa yang aktif berorganisasi. Jurnal Cakrawala Pendidikan, 34(2). (Online). (https://journal.uny.ac.id/index.php/cp/article/view/4826).

Rahmawati, E. (2018). Hubungan Gaya Belajar terhadap Indeks Prestasi Kumulatif (IPK) Mahasiswa Fakultas Kedokteran Universitas Lampung Jurnal Medula, 8(1), 7-11. 
Rahmaningsih, A. A. (2017). Pengaruh Keaktifan Berorganisasi terhadap Prestasi Akademik dalam Pandangan Hukum Islam (Studi pada Mahasiswa Fakultas Syariah Universitas Islam Negeri Raden Intan Lampung) (Doctoral Dissertation, Uin Raden Intan Lampung). (Online), (http://repository.radenintan.ac.id/704/).

Rivaldi, S., \& Khosmas, F. Y. (2013). Pengaruh Organisasi Kemahasiswaan terhadap Prestasi Belajar Mahasiswa Prodi Pendidikan Ekonomi FKIP Untan Pontianak. Jurnal Pendidikan dan Pembelajaran Khatulistiwa, 3(3). (Online), (http://jurnal.untan.ac.id/index.php/jpdpb/article/view/5093).

Safar, M. (2014) Pengaruh Keaktifan Berorganisasi Terhadap Indeks Prestasi Semester Mahasiswa Angkatan 2014 Jurusan Pendidikan Pancasila Dan Kewarganegaraan Uho Oleh: Astuti. (Online), (http://ojs.uho.ac.id/index.php/selami/article/view/8490).

Saragih, J. H., \& Valentina, T. D. (2015). Hubungan antara kecerdasan emosional dengan prestasi akademik pada mahasiswa aktivis organisasi kemahasiswaan di lingkungan Universitas Udayana. Jurnal Psikologi Udayana, 2(2). (Online), (https://ojs.unud.ac.id/index.php/psikologi/article/view/25204).

Saputro, A. R., Indriayu, M., \& Totalia, S. A. (2018). Pengaruh Keaktifan Berorganisasi Dan Prestasi Belajar Terhadap Kesiapan Kerja Mahasiswa Program Studi Pendidikan Ekonomi Angkatan 2013-2016 Universitas Sebelas Maret Surakarta. Jurnal Pendidikan Bisnis Dan Ekonomi, 4(1). (Online), (https://www.jurnal.fkip.uns.ac.id/index.php/ptn/article/view/11749).

Setyaningrum, D. F., Sawiji, H., \& Ninghardjanti, P. (2018). Pengaruh Keaktifan Berorganisasi dan Prestasi Belajar Terhadap Kesiapan Kerja Mahasiswa Program Studi Pendidikan Administrasi Perkantoran Angkatan 2013 Universitas Sebelas Maret Surakarta. JIKAP (Jurnal Informasi Dan Komunikasi Administrasi Perkantoran), 2(2). (Online), (https://jurnal.uns.ac.id/JIKAP/article/view/20798).

Sherman, K. (2017). Manfaat Membangun Relasi dalam Berbagai Aspek Kehidupan. (Online), (https://magazine.job-like.com/manfaat-membangun-relasi-dalam-berbagai-aspek-kehidupan/).

Sudirman, A., \& Muttaqiyathun, A. (2020). Pengaruh Adversity Quotient, Emotional Quotient, Dan Stres Terhadap Prestasi Akademik Mahasiswa (Studi Kasus Pada Mahasiswa Yang Mengikuti Organisasi Mahasiswa Di Universitas Ahmad Dahlan). Jurnal Fokus Manajemen Bisnis, 8(1), 1-19. (Online), (http://journal2.uad.ac.id/index.php/fokus/article/view/1578).

Solin, D. (2018). Tingkat Prestasi Mahasiswa yang Mengikuti Organisasi HMI (Studi Kasus Pada Fuf Dan Tarbiyah Uin Ar-Raniry) (Doctoral Dissertation, Uin Ar-Raniry Banda Aceh). (Online), (https://repository.arraniry.ac.id/id/eprint/8001/).

Suwarso, S. (2018). Dampak Kuliah Sambil Bekerja terhadap Indeks Prestasi Mahasiswa Perguruan Tinggi Negeri dan Swasta di Kabupaten Jember Tahun 2017. Relasi: Jurnal Ekonomi, 14(2), 15-27. (Online), (http://jurnal.stie-mandala.ac.id/index.php/relasi/article/download/261/245).

Tresnawati, E. (2019). Tips Public Speaking Dalam Presentasi Call For Paper. Bulletin Pustaka Kandaga, 1(1). (Online) (http://jurnal.unpad.ac.id/pustakakandaga/article/viewFile/23813/11830).

Wulandari, A., \& Hamzah, R. (2019). Dampak Disiplin Kerja dan Kemampuan Kerja terhadap Prestasi Kerja $\begin{array}{llll}\text { Karyawan. } \quad \text { Jurnal } & \text { Signaling, } & \text { 41-47. }\end{array}$ (http://www.ojs.stmikpringsewu.ac.id/index.php/signaling/article/view/806).

Zendrato, W. (2018). Pengaruh Organisasi Kemahasiswaan terhadap Prestasi Belajar Mahasiswa Program Studi Pendidikan Ekonomi STKIP Nias Selatan Tahun Akademik 2017/2018. Jurnal Education and Development, 3(1), 44- 44. (Online), (http://journal.ipts.ac.id/index.php/ED/article/view/137). 